\title{
Lobar lung transplantation: One size fits all
}

Hari R. Mallidi, MD, and Gita N. Mody, MD, MPH

\author{
From the Division of Thoracic Surgery, Department of Surgery, Harvard Medical School, Brigham and Women's \\ Hospital, Boston, Mass. \\ Disclosures: Authors have nothing to disclose with regard to commercial support. \\ Received for publication Oct 28, 2016; accepted for publication Oct 31, 2016. \\ Address for reprints: Hari R. Mallidi, MD, Division of Thoracic Surgery, Brigham and Women's Hospital, 75 \\ Francis St, Boston, MA 02115 (E-mail: hmallidi@partners.org). \\ J Thorac Cardiovasc Surg 2017;153:477-8 \\ $0022-5223 / \$ 36.00$ \\ Copyright $(2016$ by The American Association for Thoracic Surgery \\ http://dx.doi.org/10.1016/j.jtcvs.2016.10.059
}

Living donor-related lung transplantation is an option for patients with end-stage lung disease who would otherwise not undergo lung transplantation because of limited supply of suitable organs (Figure 1). Outcomes are comparable to those for cadaveric lung transplantation with acceptable risk for the donor. ${ }^{1}$ One barrier to broader uptake of both living and cadaveric lung transplantation includes size matching, particularly for children and small adults. Therefore, various techniques for size reduction have been developed but with variable efficacy and adoption. $^{2}$

Dr Date and colleagues ${ }^{3}$ at Kyoto University have extensive experience with living donor lobar lung transplantation (LDLLT), because societal circumstances in Japan limit organ donation after brain death. They report a series of 127 lung transplant cases over 8 years, of which more than half were LDLLT. The issue of size matching is addressed through 3 novel techniques after careful functional and anatomic measurements are taken.

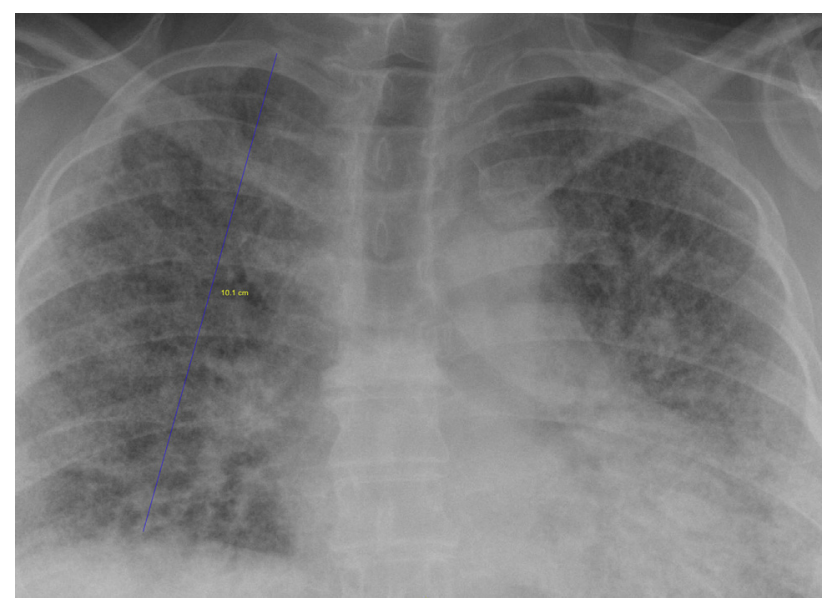

FIGURE 1. Recipient chest x-ray of a patient with idiopathic pulmonary fibrosis and a very small thoracic cavity due to shrunken lungs. Typically, these patients would wait a very long time to find suitably sized donor organs.

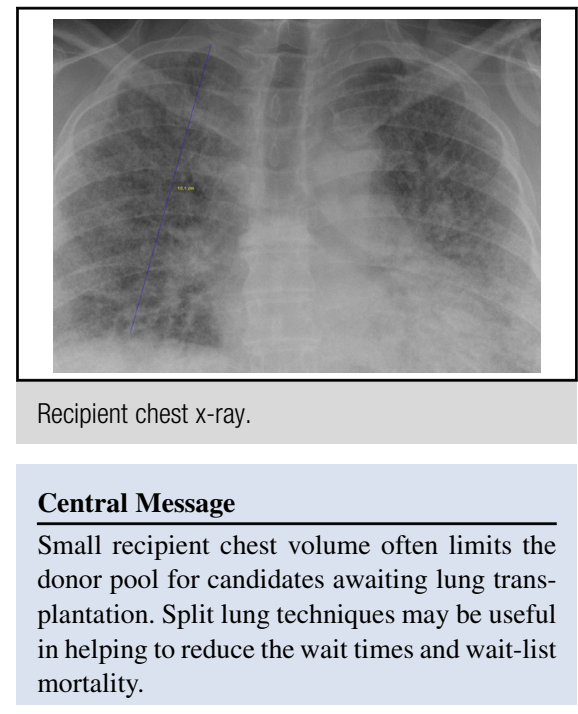

See Article page 479.

Whether too big, too small, or "just right," the authors have a solution. For oversized grafts, single lobe transplantation \pm left pneumonectomy or segmentectomy was performed. For undersized grafts, the authors performed upper lobe-sparing techniques or implantation of an inverted donor right lower lobe in the left side of the chest. In comparison with standard LDLLT, there seemed to be no difference in 5-year survival and other major outcomes for nonstandard LDLTT in this nonmatched case series.

Future studies on both standard and nonstandard LDLLT should address the determinants of long-term outcomes, including patient selection and comorbidities. It should be noted that care must be exercised when extrapolating these results, however impressive, to the broader lung transplant population. Differences in baseline demographic variables peculiar to Date and colleagues, ${ }^{3}$ home nation, such as the limited number of patients with cystic fibrosis, the relatively young age of the recipients, and the influence that short ischemic times may have on longerterm outcomes, reflect the fundamental differences between this population and the larger recipient population at large. These caveats should not diminish the potential utility of these approaches for the most disadvantaged recipients currently awaiting lung transplantation in the United States and Europe.

We appreciate the significant contribution of Date and colleagues ${ }^{3}$ to the advancement of LDLLT in this 
and other reports by their group. Their creative approach to size mismatches is instructive and provides a compelling technical review. Ultimately, a multisite study on lung transplantation for small patients may provide insight into reproducible outcomes and set new standards for lung transplantation in this population.

\section{References}

1. Bowdish ME, Pessotto R, Barbers RG, Schenkel FA, Starnes VA, Barr ML. Longterm pulmonary function after living-donor lobar lung transplantation in adults. Ann Thorac Surg. 2005;79:418-25.

2. Marasco SF, Than S, Keating D, Westall G, Whitford H, Snell G, et al. Cadaveric lobar lung transplantation: technical aspects. Ann Thorac Surg. 2012;93:1836-42.

3. Date H, Aoyama A, Hijiya K, Motoyama H, Handa T, Kinoshita H, et al. Outcomes of various transplant procedures (single, sparing, inverted) in livingdonor lobar lung transplantation. J Thorac Cardiovasc Surg. 2017;153:479-86. 